$87 \%$ regaining continence. Initially the staff had accepted the incontinence as inevitable and a nihilistic attitude had prevailed. But with increased awareness and appropriate medical and nursing support attitudes were revolutionised.

The authors estimate that as many as 10000 old people in homes in Britain might be relieved of faecal incontinence if the lessons of this research were heeded. This well conducted study deserves wide publicity and highlights the need for better education in geriatric medicine among both doctors and those concerned with residential care.

R E IRVINE

Physician in Geriatric Medicine (Retired),

Guernsey,

Channel Islands

1 Tobin GW, Brocklehurst JC. Faecal incontinence in residential homes for the elderly: prevalence, actiology and management. Age Ageing 1986;15:41-6.

2 Booth T, Barritt A, Berry S, Martin DN, Stone S. Levels of dependency of elderly people in residential homes. I Epidemiol Communiny Health 1982;36:53-7.

3 Harrison S. Avton M. The dependence of elderly people in residential homes. Nursing Times 1980;76:105-12

\section{Spoiled soft contact lenses}

A patient who damages or loses his or her own expensive hydrophilic contact lenses will be annoyed-but the complaint will be much louder if the damage is caused by drugs prescribed without appropriate warning.

Rifampicin may cause reddish discoloration of the urine, sputum, and tears. It may produce permanent orange discoloration of soft contact lenses, and data sheets advise that "the patient should be forewarned of these possible effects." Similar discoloration has been reported with sulphasalazine. ${ }^{2}$ Presumably other drugs which discolour tears or body fluids may also affect soft contact lenses.

It has long been known by both optical and medical contact lens practitioners, but not necessarily by all doctors, that fluorescein stains soft lenses and may permanently spoil them. A high molecular weight dimer of fluorescein (Fluorexan) does not concentrate as rapidly in soft lenses and may be used for fitting. ${ }^{3}$ Alternative techniques avoiding the need for dyes are more usually employed. Rose Bengal is similarly contraindicated-but the concentrated dye may be removed by repeated leaching processes.

Topical preparations may also spoil lenses. Adrenochrome staining of the contact lenses of patients using adrenaline drops for treating glaucoma was reported in $1974^{4}$ and 1976. . $^{5}$ Melanin deposits may also appear in the conjunctiva of patients using adrenaline; when the drug is absorbed by these lenses ocular enzymes cause oxidation and polymerisation to a type of melanin. Though the melanin is locked into the lens, it may be cleared with hydrogen peroxide, which breaks the molecule into water soluble elements. In practice, such lenses are usually discarded. ${ }^{+}$The prodrug dipivalyl epinephrine (dipivefrine hydrochloride) has been used successfully without staining soft lenses, ${ }^{6}$ but the inclusion of benzalkonium chloride as a preservative in some preparations contraindicates its use.

Soft contact lenses are spoiled in many other ways: some are "natural causes" such as the deposition of calcium on the surface or the build up of organic matter from the tear film and shed surface cells of the cornea and conjunctival sac. Such spoilation is of interest to both wearers and prac- titioners. The iatrogenic spoiling of soft lenses is much less well known, but of greater importance to the medical profession in general.

The number of contact lens wearers in this country is not known with any certainty, but $6 \%$ to $7 \%$ of people requiring refractive corrections are thought to wear contact lenses (in the United States the figure is double). There may be up to two and a half million contact lens wearers, and $60 \%$ of all contact lenses sold are soft. This figure does not reflect the proportion of wearers using soft lenses because these require more frequent replacement. Clearly a million or more people may be at risk of having their lenses spoiled by inadvertent use of drugs. The use of hard (polymethylmethacrylate) contact lenses, which may be worn by many patients throughout the waking day, avoids all the above disadvantages. Furthermore, patients will then have better vision through more durable, cheaper lenses which are easier to handle, sterilise, and store, and subject to none of the iatrogenic problems that will become commoner if the number of people taking drugs and wearing soft lenses increases. Soft lenses are ideal for the patient who cannot tolerate hard ones. Many wearers, however, have been fitted with soft lenses without a full and frank explanation of the options available. Soft lenses are certainly more comfortable at the initial fitting and in the early period of acclimatisation. This perpetuates the commercial and media pressure to sell this type of lens. The longer term problems may outweigh the short term gain, and iatrogenic spoiling of lenses is one factor to be put in the balance sheet.

D V INGRAM

Consultant Ophthalmic Surgeon,

Sussex Eye Hospital,

Brighton BN2 5BF

1 Lyon RW. Orange contact lenses from rifampicin. .N Engl F .Med 1979;300:372-3.

2 Riley SA, Flegg PJ. Mandal BK. Contact lens staining due to sulphasalazine. Lancet 1986;i:972.

3 Krezanoski JZ. Topical medications. Int Ophthalmol Clin 1981;21:173-6.

+ Sugar J. Adrenechrome pigmentation of hydrophilic lenses. Arch (phthalmol 1974:91:11-2.

Miller D. Brooks SM. Mobilia E. Adrenochrome staining of soft contact lenses. Ann Ophthalmol 1976:8:65-7.

6 Newton MJ. Nesburn AB. Lack of hidrophilic lens discoloration in patients using dipvalyl epinephrine for glaucoma. Am 7 Ophthalmol 1979;87:193-5.

\section{A senseless sacrifice: the fate of intercalated degrees}

Among the many current threats to academic medicine is one that will be more harmful than it might seem. Each year about $10 \%$ of medical students decide to add an extra 12 months to their course and work for an "intercalated" honours degree in science (or occasionally subjects such as psychology or medical history). At Oxford, Cambridge, and Nottingham universities an honours degree year is built into the course and applies to all students. At the other British universities the intercalated year is optional, and for that reason education authorities rarely agree to pay the fees or give a grant for the extra time. Most students in England and Wales have been supported by the Medical Research Council, while in Scotland they have been funded by the Scottish Education Department.

Now it seems that the Medical Research Council is being pressed to stop the funding - not because anybody disputes the value of intercalated degrees but simply because of the page in the government's account book from which the money comes. 
At the end of the 1970s the MRC was funding nearly 400 students at a cost of about $£ 800000$ (around $1 \%$ of its budget). A few students were funded by local education authorities, "soft money," or themselves. The MRC had started supporting students in 1964 after prompting from the then Ministry of Education and in its first year supported just 12. Once this source of funding was advertised the numbers grew rapidly, reaching a peak in 1979-80, and the proportion doing the degrees became similar in all medical schools, though each medical school was left entirely to itself to decide which students would be supported.

In 1980 the MRC decided that the money it was spending on these students was growing too fast, and it capped the number at 380 . Since then their numbers have been reduced by $10 \%$ a year. Some 304 will be supported in 1986-or perhaps none at all. The question mark is due to a decision by the Exchequer and Audit Department (now the National Audit Office) to question the council's funding of these students. It is arguing not only that the MRC should not be paying this money because it is not for research but also that it is insufficiently discriminating in where the money goes. The MRC is now waiting to see whether its reply to this charge will be accepted. If it is not the matter will be referred to the Public Accounts Committee, and the council could be told to stop the funding.

The MRC responded to the challenge by informing all deans that it would have to start discriminating between schools, departments, and courses. Conditions attached to funding would include the schools explaining how students will be selected, the courses including some research that would have to be written up, and reports being produced on the outcome of each award. The council also announced its intention to monitor results. Clearly such a system would consume time and money that could be better spent.

The MRC has also looked for other ways of funding the students-and drawn something of a blank. For the Department of Education and Science to take over the funding, even if the will and the money were available, would require legislation, and hard pressed local education authorities, the other potential source, are unlikely to support many students when the grants remain discretionary.

The Kafkaesque lunacy of all this is that no one seems to dispute the value of these degrees. A paper we publish today (p 1646) shows not only that $40 \%$ of graduates who had done intercalated degrees in pathology in Edinburgh went into academic medicine but also that they did better in the rest of the academic curriculum than a group of students of matched ability who did not do intercalated degrees. A study from Queensland of 99 doctors who had taken degrees in basic medical sciences showed that they were 20 times more likely than their controls to go into full time research, four times more likely to graduate with an honours degree, and much more likely to have published papers in refereed scientific journals. ' Further British research has also shown that of a sample of 262 doctors in research orientated posts almost a third had taken intercalated degrees. ${ }^{2}$

Many of these self selected doctors might, of course, have gone into academic medicine anyway, but much of the value of these courses is not quantifiable in these ways. Most of those who do intercalated degrees (and I was one) speak very positively of the experience. "That was the year," they say, "that I learnt to think and to question and to find out things for myself." That is where the degrees may be so importantthey prepare students for a lifetime of learning. Many are driven into intercalated degrees by the unremitting dullness of preclinical courses, but many emerge newly inspired and ready not only to soak up clinical medicine but also to push 무 forward its boundaries.

For these degrees to be lost simply for lack of somebody with common sense in government would be a tragedy. Somebody-probably the education departments-must pick up the bill.

Assistant editor, $B M \mathcal{F}$

RICHARD SMITH

1 Eaton DG, Thong YH. The bachelor of medical science research degree as a start for clinician scientists. Med Educ 1985; 19:445-51.

Wakeford $\mathrm{R}$, Lyon J, Evered D, Saunders $\mathrm{N}$. Where do medically qualified researchers come from? Lancet 1985;ii:262-3.

\section{Adolescent suicide: preventive considerations}

Suicide in prepubertal children is rare, and the rates appear stable over time..$^{1.3}$ By contrast, the rates of suicide and attempted suicide in older teenagers have increased appreciably during the past 30 years in most countries where accurate statistics are kept, whereas in older people they have remained stable or declined. ${ }^{34}$ In 1984 in England and Wales 112 people under 20 killed themselves. 5 In Japan, with roughly twice the population, 572 under 19 year olds killed themselves. ${ }^{6}$ In the United States suicide is now the third most common cause of death in 15-24 year old white young men.'

In most countries suicides by men outnumber those by women by at least 2:1, although attempted suicide is far commoner in girls. The methods used by boys and men are more violent (firearms, jumping from high places, and hanging) and more likely to result in death. Women and girls favour overdosing, where resuscitation is more likely. ${ }^{3}$ The two groups, suicide and attempted suicide, vary in many ways but $46 \%$ of young suicides (under 14 ) had made threats or attempts before the act, ${ }^{1}$ and in the follow up study of youngsters aged $10-20$ who had attempted suicide $10 \%$ of the boys and 3\% of the girls eventually killed themselves, usually within two years. ${ }^{8}$ Repetition rates in a later study were much lower $(0.24 \%)^{9}$ probably because the earlier one included all forms of attempted suicide.

The impact on those most closely connected with a young person who kills himself are profound. Family, teachers, friends, and workmates experience guilt and stigma. Reactions of denial and blame are common. Mourning may be more difficult for the family because friends avoid talking to them about such deaths.

If we are to prevent or reduce the number of adolescent suicides we must understand the causes. The problems of studying causation when of necessity the study must be retrospective have been summarised by Hawton. ${ }^{3}$ Among adults committing suicide $90 \%$ have psychiatric disorders, especially depression and schizophrenia. ${ }^{10}$ The rate in young people is probably less than $50 \%$ but there is often a family history of both psychiatric disorder and suicidal behaviour. ${ }^{11}$ There may therefore be a genetic predisposition to depression or other psychiatric disorders. In addition the behaviour (taking pills, attempting suicide) may be imitated. Finally, living with a mentally ill parent, especially a single parent, may be intolerable. Most young people who kill themselves have high levels of family disruption and in addition may 